\title{
Quality of Life in Family Caregivers of Adolescents with Depression in China: A Mixed-Method Study
}

This article was published in the following Dove Press journal:

Patient Preference and Adherence

\author{
Yinying Zhang' \\ Min Yang' \\ Xin Guo ${ }^{2}$ \\ Qiongni Chen ${ }^{3}$ \\ 'Xiangya Nursing School of Central \\ South University, Changsha, Hunan \\ Province, People's Republic of China; \\ ${ }^{2}$ Huashan Hospital of Fudan University, \\ Shanghai City, People's Republic of China; \\ ${ }^{3}$ Clinical Nursing Teaching and Research \\ Section, The Second Xiangya Hospital of \\ Central South University, Changsha, \\ Hunan Province, People's Republic of \\ China
}

Purpose: In this study, we investigated quantitatively the quality of life (QoL) and its influencing factors among Chinese family caregivers who care for adolescents with depression (AWD) and we explored qualitatively their care-giving experiences.

Methods: The study was a mixed method with convergent parallel design. The sociodemographic characteristics, QoL, caregivers' burden, family functioning, positive and negative affects were assessed by using questionnaires on 240 family caregivers of AWD in China. Twelve of these family caregivers were interviewed by using a semi-structured guide to explore their care-giving experiences.

Results: The mean score among family caregivers of AWD for physical QoL was 65.18 and 59.42 for mental QoL, which was significantly lower than the Chinese norms for QoL. Multiple regression analysis demonstrated that course of disease of AWD, caregivers' educational qualification, family functioning, positive affect and care-giving burden accounted for $57 \%$ of the variance in physical QoL. Suicide history of AWD, caregivers' educational qualification, negative affect, positive affect, care-giving burden and family functioning accounted for $54 \%$ of the variance in mental QoL. Four major themes of the care-giving experiences emerged: lack of knowledge about depression, being overwhelmed emotionally with psychological burden, the devastating impact of illness on family, and the perceived benefits of care-giving.

Conclusion: The QoL among family caregivers of AWD in China was low. It is necessary for health-care professionals to pay more attention to the QoL of family caregivers who care for AWD.

Keywords: adolescent, depression, caregiver, quality of life, caring experience

\section{Introduction}

Adolescence is the typical age of onset of depression. ${ }^{1}$ The worldwide prevalence of the major depressive disorder in children and adolescents has been reported to be $1.3 \%{ }^{2}$ In China, the pooled point prevalence of major depressive disorder in children and adolescents was similar to worldwide figures. Based on the point prevalence of $1.3 \%$, there are about 2.3 million adolescents with major depressive disorder in China. ${ }^{3}$ Adolescents with depression (AWD) often exhibit more than one core symptom, such as poor school performance, running away from home, and hostility towards family. ${ }^{4}$ Compared with adults with depression, AWD are at a higher risk of future negative outcomes, such as a greater likelihood of attempted suicide and other psychiatric co-morbidity. ${ }^{5}$ These symptoms and risks are of concern to family caregivers of AWD. Since AWD often need long-term medication and psychotherapy, ${ }^{6}$ their family caregivers bear the responsibility of caring 
over a long term. In China, cultural tradition influences familial responsibility, which dictates that the home-based rehabilitation model has become a custom. Because of insufficient health resources and social support, family members, especially parents, play a vital role in caring for AWD. ${ }^{7,8}$

Meeting the high care demands of AWD requires much time, effort, and patience, which often results in adverse effects for family caregivers, such as the financial burden of treatment costs, disruption in their employment, and diminished family relationships. ${ }^{9}$ Some caregivers of patient with depression even described their caring experience as a "turbulent life", which was embodied in daily life's hardship, too much attention to the patients, and concern about the patient's current and future conditions. ${ }^{10}$ Parents of AWD may feel profound guilt about not being able to prevent their children from having depression and feel they are not good parents. ${ }^{11}$ As a result, parents often sacrifice their own wellbeing for the sake of their children. These adverse effects can affect the quality of life (QoL) among family caregivers, ${ }^{12}$ and may have a direct influence on the symptoms of AWD and an indirect influence on QoL of AWD. ${ }^{13}$ Thus, paying more attention to the QoL of family caregivers of AWD is necessary.

In previous studies, the QoL of caregivers of adults with depression and was significantly poorer than the general population. ${ }^{14-16}$ However, few studies have investigated the QoL and its influential factors of caregivers of AWD. Zhang and Tang found that some demographic factors affected the QoL of caregivers of adults with depression, including caregivers' age, income and education level. ${ }^{17}$ Moreover, social support, care-giving burden, and caregivers' psychological state have been shown to be the influencing factors of QoL of caregivers of adults with severe mental illness. ${ }^{12,18}$ Although family functioning of patients with depression has an impact on QoL of caregivers, ${ }^{19}$ up to now we know little about the impact of family functioning of caregivers of patients with depression. Besides the negative influence of care-giving, some caregivers have described the benefits of care-giving, ${ }^{20}$ but the effect of benefits of care-giving on caregivers' QoL has less been explored.

To better understand QoL among caregivers of AWD, the study design combined a quantitative and qualitative approach. Therefore, we aimed to 1) investigate QoL and its influencing factors among caregivers of AWD in China and 2) explore the differences in caregivers' QoL between AWD and adults with depression, and how these influencing factors affect the QoL among the caregivers of AWD.

\section{Materials and Methods Design}

The study was a mixed method with a convergent parallel design. The mixed approach was chosen to achieve a thorough integration of findings from both quantitative and qualitative methods, resulting in a more comprehensive interpretation of the study-related questions. ${ }^{21}$ Quantitative questionnaires were used to measure the QoL and related factors of family caregivers with AWD. In-depth qualitative interviews were conducted to better understand the care-giving experiences of family caregivers of AWD. The study was reviewed and approved by IRB of behavioral and nursing research in School of Nursing of Central South University, China.

\section{Participants for Quantitative Investigation}

A total of 240 family caregivers of AWD were recruited from the mental health center of a tertiary hospital in China from March and December 2017. The inclusion criteria were: 1) older than 18 years; 2) primary caregivers of an adolescent ( $\geq 12$ and $\leq 18$ years) diagnosed with depression according to the Diagnostic and Statistical Manual of Mental Disorders-IV (DSM-IV) and was in convalescence diagnosed by the doctor; 3) looking after more than 3 months; 4) able to comprehend and complete the questionnaires relevant to this study. Caregivers with mental disorders or cognitive impairment and paid caregivers were excluded from the study, such as home nurses, nursing home workers, or professional caregivers. According to the method of sample size calculation of multiple linear regression, the sample size needs to be 5 to 10 times of the independent variables. ${ }^{22}$ Our study had a total of 20 independent variables ( 16 for demographic profile and 4 for the other questionnaires). Hence, we needed 100 to 200 samples. Of the 250 eligible participants who participated in this study, a total of 240 participants completed the valid questionnaires ( 10 were excluded due to incomplete questionnaires) for a $92.3 \%$ response rate.

\section{Participants for Qualitative Interview}

Besides the above-mentioned inclusion and exclusion criteria, participants were recruited by using a purposive sampling technique according to the variety of their QoL as well as age, gender, educational level, and relationship with AWD. Because the QoL among the Chinese caregivers of adults with depression was far below the Chinese norms (77.54 \pm 15.96 for physical QoL and 71.29 \pm 17.86 for mental QoL), ${ }^{23,24}$ we took the low-norms (61.58 for physical QoL 
and 53.43 for mental QoL) and norms (77.54 for physical QoL and 71.29 for mental QoL) to be our reference values. Hence, we included the following four types of participants: those with both physical and mental QoL higher than the norms; those with both physical and mental QoL lower than the norms; those with only physical QoL lower than the norms; and those with only mental QoL lower than the norms. Data saturation was used to determine the sample size for qualitative interviews. ${ }^{25}$ Finally, twelve of the 240 participants were interviewed in-depth to explore their caregiving experiences. Detailed information about the 12 caregivers is presented in Table 1.

\section{Research Tools}

Based on literature review ${ }^{17}$ and expert consultation, the following caregivers' demographic data were collected by self-report, involving caregivers' age, gender, relationship with the AWD, educational level, marital status, employment status, family monthly income and caregivers' knowledge level about depression. We also collected the following demographic information from AWD, including their age, gender, course of disease (months), suicide history, first-episode or not and only child or not, data source (outpatient or inpatient).

Caregivers' QoL was measured with the Short Form 36 Health Survey Questionnaire (SF-36), ${ }^{26}$ which is composed of eight subscales: physical functioning (PF), bodily pain (BP), role-physical (RP), general health (GH), role-emotional (RE), social functioning (SF), vitality (VT) and mental health (MH). The eight subscales can be combined to form two components: physical and mental. The physical component summary (PCS) means physical QoL and consists of the PF, BP RP and GH subscales. The mental component summary (MCS) means mental QoL and consists of the VT, SF, RE and MH subscales. Scores can range from 0 to 100; higher scores indicate higher reported QoL. SF-36 has been shown to have good reliability and validity on QoL of primary caregivers of the elderly with cerebrovascular disease or diabetes. ${ }^{27}$ The Chinese version of the SF-36 was translated and validated by $\mathrm{Li}$ et al, ${ }^{28}$ and the Cronbach's alpha ranged from 0.72 to 0.88 . The range of 2-week test-retest reliability was from 0.66 to 0.94 .

The Positive and Negative Affect Scale (PANAS) measures caregivers' positive and negative affect in daily life. ${ }^{29}$ The PANAS consists of 10 positive emotion items and 10 negative emotion items. The response options range from 1 (very slightly or not at all) to 5 (extremely). Higher scores on the positive affect items indicate a more positive and happy emotional state (positive affect). Higher scores on the negative affect items indicate distress and a negative emotional state (negative affect). The PANAS has been shown to have good reliability and validity in mental health studies on caregivers of people diagnosed with severe neuromotor and cognitive disorders. ${ }^{30}$ The Chinese version of the PANAS has demonstrated good internal consistency reliability with a Cronbach's alpha of $0.82 .{ }^{31}$

The Zarit Burden Interview (ZBI) was used to assess the burden level of caregivers. ${ }^{32}$ The ZBI scale consists of 22 items, examining caregivers' burden in physical, mental, social and economical aspects. The response options range from 0 (not at all) to 4 (always). Scores can range from 0 to 88 . Higher scores indicate greater perceived burden. The total score can be categorized into four groups: no burden (less than 20), mild burden (20-39), moderate burden (40-59), and heavy burden (60 or greater). The ZBI was validated with family caregivers

Table I General Information of Interviewed Caregivers

\begin{tabular}{|c|c|c|c|c|c|c|}
\hline Number & Age (Years) & Gender & Relationship with the Patient & Educational Level & Physical QoL & Mental QoL \\
\hline$I^{\mathrm{a}}$ & 48 & Female & Mother & University & 77.75 & 90.00 \\
\hline $2^{\mathrm{a}}$ & 41 & Female & Mother & High school & 74.00 & 83.13 \\
\hline $3^{b}$ & 44 & Male & Father & Junior high school & 49.75 & 74.46 \\
\hline $4^{\mathrm{a}}$ & 43 & Female & Mother & University & 66.00 & 54.29 \\
\hline $5^{c}$ & 43 & Female & Mother & University & 54.00 & 46.88 \\
\hline $6^{d}$ & 37 & Female & Mother & University & 66.25 & 31.63 \\
\hline $7^{\mathrm{b}}$ & 38 & Female & Mother & Junior high school & 60.25 & 55.46 \\
\hline $8^{c}$ & 63 & Female & Grandmother & Primary school & 36.75 & 38.21 \\
\hline $9^{c}$ & 40 & Male & Father & Junior high school & 40.50 & 47.38 \\
\hline $10^{\mathrm{a}}$ & 40 & Female & Mother & High school & 65.25 & 64.08 \\
\hline $11^{d}$ & 25 & Female & Sister & University & 74.75 & 51.21 \\
\hline $12^{\mathrm{a}}$ & 42 & Female & Mother & Primary school & 85.50 & 86.75 \\
\hline
\end{tabular}

Notes: ${ }^{a}$ Subjects with both physical and mental QoL higher than the norms. 'Subjects with physical QoL lower than the norms but mental QoL higher than the norms. 'Subjects with both physical and mental QoL lower than the norms. 'Subjects with mental QoL lower than the norms but physical QoL higher than the norms. 
of schizophrenia individuals. ${ }^{33}$ For the Chinese version, Cronbach's alpha was $0.875 .^{34}$

The Family APGAR index (APGAR) was used to assess family functionality, the emotional, communicative and social interactions between patients and their family members. ${ }^{35}$ The APGAR consists of five items that assess adaptation, partnership, growth, affection and resolve. Respondents rated each item from 0 to 2, yielding a total score that can range from 0 to 10 . Good family functionality is classified as a score of 7-10. Moderate family dysfunction is classified as a score of 4-6. High family dysfunction is classified as a score of $0-3$. The APGAR was validated with family caregivers of patients with schizophrenia. ${ }^{36}$ The Chinese Family APGAR has been validated and has been shown to have adequate internal consistency reliability (Cronbach' alpha $=0.86){ }^{37}$

\section{Data Collection}

The first author and the second author recruited potential participants in-person from both the inpatient and outpatient departments. The first author scanned the potential participants. If they were qualified, they were required to fill in the quantitative questionnaires which took 10-15 mins. The second author calculated the QoL scores concurrently. After the calculation, the two authors decided whether to collect their qualitative data jointly based on their QoL scores, as well as their age, gender, relationship with the patient and educational level. The interviews were conducted by the first author following the quantitative data collection immediately.

We orally invited 12 caregivers. They were first informed of the purpose and procedures of the study, and were guaranteed the right to withdraw at any time without negative consequences. They were informed that all transcripts, the analysis of data and presentation of results were anonymous. They volunteered for the study and verbal consent was obtained prior to interviews. The individual interviews were conducted by the first author in a private room (the head nurse's office in the inpatient department or a counseling room in the outpatient department). In-depth interviews were audio-recorded, conducted in Mandarin (the required language of working environments in China). Transcription of the interview was performed before the next interview, and every new interview was compared with the previous one until no new information emerged. Each interview took between 45 mins to $1 \mathrm{hr}$. The semistructured interview guide was designed based on a literature review and expert consultation. Generally, the study participants led the discussion, with the interviewers prompting as needed. Specific questions were: "How did you feel when you learned your adolescent was initially diagnosed with depression?", "What have been the effects of care-giving on your physical and mental health?", "How has care-giving influenced your life, family and job?", "What difficulties or troubles have you encountered as a caregiver and what kind of support do you need?", "What have you learned as a caregiver?".

\section{Data Analysis}

Quantitative data were analyzed by using IBM SPSS version 18.0. Descriptive statistics were calculated to describe the study variables: demographics, positive affect, negative affect, caregiver burden, and family functioning. Independent sample t-tests were computed to compare the differences in $\mathrm{QoL}$ between family caregivers and Chinese norms. The univariate analysis was performed on the demographic factors that may influence caregivers' QoL. Correlation analysis was used to measure the relationship between caregivers' QoL and their care-giving burden, family functioning, positive and negative affect. Stepwise multiple regression analysis was used to analyze the influencing factors of caregivers' QoL. Statistical significance was set as $p<0.05$.

The audio recordings and notes from the in-depth interviews were transcribed verbatim by the first author who conducted the interviews. To ensure anonymity and confidentiality, the transcripts were numbered. Inductive thematic analysis occurred after data saturation. The first and second authors coded the transcripts separately to identify the main themes, using NVIVO 11.0 software. The corresponding author and the third author reviewed the audio-recordings and transcripts to ensure the themes were representative. The researcher team (included the first, second and third authors, and the corresponding author) discussed the disagreements and finalized the themes after consensus.

\section{Results}

\section{Demographic Profile Family Caregivers and Adolescents with Depression}

In Table 2, the average age of the family caregivers was 43.57 $(\mathrm{SD}=7.77)$ years old. A majority of the caregivers were females $(72.5 \%)$, mothers $(64.6 \%)$, married $(84.6 \%)$, unemployed (56.7\%), and had a junior high school degree (44.2\%). Over half of caregivers had a family monthly income of less than \$444. Caregivers' disease-related knowledge level about 
Table 2 Demographic Characteristics of Caregivers $(n=240)$

\begin{tabular}{|c|c|c|c|}
\hline Sample Characteristics & n (\%) & Mean (SD) & Range \\
\hline Age (years) & & $43.57(7.77)$ & $19-72$ \\
\hline \multicolumn{4}{|l|}{ Gender } \\
\hline Male & $66(27.5)$ & & \\
\hline Female & $174(72.5)$ & & \\
\hline \multicolumn{4}{|l|}{ Relationship with the AWD } \\
\hline Father & $58(24.2)$ & & \\
\hline Mother & $155(64.6)$ & & \\
\hline Grandparents & $15(6.3)$ & & \\
\hline Others & $12(5.0)$ & & \\
\hline \multicolumn{4}{|l|}{ Educational qualification } \\
\hline Primary school and below & $45(18.8)$ & & \\
\hline Junior high school & $106(44.2)$ & & \\
\hline High school & $39(16.3)$ & & \\
\hline University and above & $50(20.8)$ & & \\
\hline \multicolumn{4}{|l|}{ Marital status } \\
\hline Unmarried & $10(4.2)$ & & \\
\hline Married & $203(84.6)$ & & \\
\hline Divorced & $22(9.2)$ & & \\
\hline Widowed & $5(2.1)$ & & \\
\hline \multicolumn{4}{|l|}{ Employment status } \\
\hline Employed & $104(43.3)$ & & \\
\hline Unemployed & $136(56.7)$ & & \\
\hline \multicolumn{4}{|l|}{ Family monthly income (US\$) ${ }^{\mathrm{a}}$} \\
\hline$\leq 444^{\mathrm{b}}$ & $125(52.1)$ & & \\
\hline$>444$ & 115 (47.9) & & \\
\hline \multicolumn{4}{|l|}{ Caregivers' disease-related knowledge level about depression (self-assessment) } \\
\hline Fully unknown & $94(39.2)$ & & \\
\hline Know little & $130(54.2)$ & & \\
\hline Know a lot & $10(4.2)$ & & \\
\hline Fully know & $6(2.5)$ & & \\
\hline
\end{tabular}

Notes: ${ }^{\mathrm{a}}$ The United States dollar based on a currency exchange rate of 6.7518 Yuan RMB to US $\$ 1.00$ in $2017 .{ }^{\mathrm{b}}$ The minimum per capita income in Hunan province, China in $2016 .{ }^{46}$

depression was as follows: fully unknown $(39.2 \%)$; know little (54.2\%); know a lot (4.2\%); fully know (2.5\%).

In Table 3, the mean age of the AWD was $15.37(\mathrm{SD}=$ $1.95)$ years old and the mean course of disease was 12.70 $(\mathrm{SD}=7.49)$ months. A majority of AWD were females (54.6\%), not only child (57.5\%), first-episode $(56.7 \%)$, inpatient (70\%), and had no suicide history (59.6\%).

\section{QoL Among Caregivers}

In Table 4, the mean score for physical QoL among the family caregivers was $65.18(\mathrm{SD}=19.12)$. The mean score for mental QoL among the family caregivers was 59.42 (SD $=21.22$ ). For the physical QoL, the mean score of PF was highest $(\bar{X}=82.93, S D=15.42)$, while the mean score of $R P$ was lowest $(\bar{X}=50.73, \mathrm{SD}=35.97)$. For the mental QoL, the mean score of SF was highest $(\bar{X}=77.71, S D=24.69)$, while the mean score of $\mathrm{RE}$ was lowest $(\overline{\mathrm{X}}=50.97, \mathrm{SD}=37.95)$. The caregivers' mean scores on all eight QoL dimensions were significantly lower than the Chinese norms $(p<0.01){ }^{24}$

\section{Care-Giving Burden, Family Functioning, Positive and Negative Affect}

The mean score for caregiver burden was 31.74 (SD $=15.06$ ). The caregiver burden scores for $78.8 \%$ of the caregivers were in low, moderate and heavy ranges, and $21.3 \%$ caregivers felt no burden. 
Table 3 Demographic Characteristics of Adolescents with Depression $(n=240)$

\begin{tabular}{|l|l|l|l|}
\hline Sample Characteristics & n (\%) & Mean (SD) & Range \\
\hline Age (years) & & $15.37(1.95)$ & $12-18$ \\
\hline $\begin{array}{l}\text { Gender } \\
\text { Male } \\
\text { Female }\end{array}$ & $\begin{array}{l}109(45.4) \\
131(54.6)\end{array}$ & & \\
\hline $\begin{array}{l}\text { Only child } \\
\text { Yes } \\
\text { No }\end{array}$ & $102(42.5)$ & & \\
\hline $\begin{array}{l}\text { Course of disease (months) } \\
138(57.5)\end{array}$ & & $0.5-132$ \\
\hline $\begin{array}{l}\text { Suicide history } \\
\text { Yes }\end{array}$ & $97(40.4)$ & & \\
No & $143(59.6)$ & & \\
\hline $\begin{array}{l}\text { First-episode } \\
\text { Yes } \\
\text { No }\end{array}$ & $\begin{array}{l}136(56.7) \\
104(43.3)\end{array}$ & & \\
\hline $\begin{array}{l}\text { Data source } \\
\text { Outpatient } \\
\text { Inpatient }\end{array}$ & $\begin{array}{l}72(30.0) \\
168(70.0)\end{array}$ & & \\
\hline
\end{tabular}

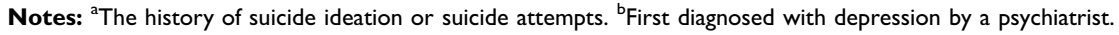

Table 4 Comparison of Quality of Life Mean Scores Between Caregivers and Chinese Norms

\begin{tabular}{|c|c|c|c|c|}
\hline QoL Subscale & Caregivers' Score (X士SD) & Chinese Norm (X士SD) & $\mathbf{t}$ & P-values (Independent $t$-test) \\
\hline PF & $82.93 \pm 15.42$ & $89.01 \pm 15.72$ & -6.086 & 0.000 \\
\hline SF & $77.71 \pm 24.69$ & $84.60 \pm 18.15$ & -3.947 & 0.007 \\
\hline BP & $72.90 \pm 16.25$ & $80.40 \pm 19.7$ & -6.725 & 0.000 \\
\hline VT & $54.73 \pm 21.07$ & $71.15 \pm 18.09$ & -11.963 & 0.000 \\
\hline $\mathrm{MH}$ & $54.27 \pm 19.01$ & $75.23 \pm 16.69$ & -16.892 & 0.000 \\
\hline $\mathrm{GH}$ & $54.07 \pm 27.95$ & $66.03 \pm 20.87$ & -6.602 & 0.000 \\
\hline RE & $50.97 \pm 37.95$ & $77.04 \pm 35.45$ & -10.625 & 0.000 \\
\hline RP & $50.73 \pm 35.97$ & $81.99 \pm 31.65$ & -13.468 & 0.000 \\
\hline PCS & $65.18 \pm 19.12$ & $79.36 \pm 17.00$ & -11.105 & 0.000 \\
\hline MCS & $59.42 \pm 21.22$ & $77.00 \pm 17.42$ & -12.833 & 0.000 \\
\hline
\end{tabular}

Abbreviations: PE, physical functioning; SF, social functioning; BP, bodily pain; VT, vitality; MH, mental health; GH, general health; RE, role-emotional; RP, role-physical; PCS, physical component summary (consists of PF, BP, RP and GH); MCS, mental component summary (consists of the VT, SF, RE and MH).

There were $29.6 \%$ of caregivers who had good family function as defined by the APGAR index. And $70.4 \%$ of caregivers had moderate and high family dysfunction.
The mean score for positive affect among caregivers of AWD was $21.62(\mathrm{SD}=6.20)$. The mean score of negative affect among caregivers of AWD was 24.57 ( $\mathrm{SD}=8.92$ ).

Table 5 Correlation Analysis of Care-Giving Burden, Family Functioning, Positive and Negative Affect on Caregivers' QoL

\begin{tabular}{|l|l|l|l|l|}
\hline Variables & Care-Giving Burden & Family Functioning & Positive Affect & Negative Affect \\
\hline Physical QoL & -0.594 & 0.551 & 0.519 & -0.494 \\
Mental QoL & -0.634 & 0.571 & $0.5 \mathrm{II}$ & -0.523 \\
\hline
\end{tabular}

Note: All values are statistically significant at $\mathrm{P}<0.01$ (two-tailed). 
Table 6 Multivariate Stepwise Regression Analysis of Caregivers' Physical Quality of Life

\begin{tabular}{|l|l|l|l|}
\hline Variables & Beta & t & P-values \\
\hline Care-giving burden & -0.315 & -5.676 & 0.000 \\
Positive affect & 0.269 & 5.039 & 0.000 \\
Family functioning & 0.238 & 4.499 & 0.000 \\
Caregivers' education level & 0.192 & 4.346 & 0.000 \\
Patients' course of disease & -0.102 & -2.283 & 0.023 \\
\hline
\end{tabular}

Abbreviation: Beta, standardized beta.

Table 7 Multivariate Stepwise Regression Analysis of Caregivers' Mental Quality of Life

\begin{tabular}{|l|l|l|l|}
\hline Variables & Beta & t & P-values \\
\hline Negative affect & -0.143 & $-2.26 \mathrm{I}$ & 0.025 \\
Care-giving burden & -0.289 & -4.238 & 0.000 \\
Positive affect & 0.158 & 2.786 & 0.006 \\
Caregivers' education level & 0.090 & $1.97 \mathrm{I}$ & 0.049 \\
Family functioning & 0.268 & 4.918 & 0.000 \\
Suicide history & -0.093 & -2.024 & 0.044 \\
\hline
\end{tabular}

Abbreviation: Beta, standardized beta.

\section{Effects of Demographic Data on Physical QoL and Mental QoL Among \\ Caregivers}

Univariate Analysis showed that the caregivers' physical QoL was shown to be related to the following demographic factors: course of disease $(p=0.001)$ of AWD; first-episode or not $(p=0.004)$ of AWD; suicide history or not $(p=0.022)$ of AWD; caregivers' educational qualification $(p=0.000)$; family monthly income $(p=0.000)$.

On the other hand, family caregivers' mental QoL was shown to be related to the following demographic factors: first-episode or not ( $p=0.001)$ of AWD; suicide history or not $(p=0.000)$ of AWD; caregivers' educational qualification $(p=0.001)$; family monthly income $(p=0.000)$.

\section{The Relationship Between Caregivers' QoL and Their Care-Giving Burden, Family Functioning, Positive and Negative Affect}

Physical QoL and mental QoL among caregivers were negatively correlated with caregivers' negative affect and caregivers' burden, and were positively correlated with caregivers' positive affect and family functioning (shown in Table 5).

\section{Influencing Factors of Physical QoL}

\section{Among Caregivers}

Results of a stepwise regression analysis revealed that $57 \%$ of the variance in physical QoL was explained by patients' course of disease $(\beta=-0.102)$, caregivers' education level $(\beta=0.192)$, positive affect $(\beta=0.269)$, care-giving burden $(\beta=-0.315)$ and family functioning $(\beta=0.238)(F=61.260$, $p=0.0005, R^{2}=0.572$ ) (shown in Table 6).

\section{Influencing Factors of Mental QoL Among Caregivers}

Results of a stepwise regression analysis revealed that $54 \%$ of the variance in mental QoL was explained by suicide history of AWD ( $\beta=-0.093)$, caregivers' education level $(\beta=0.090)$, positive affect $(\beta=0.158)$, negative affect $(\beta=-0.143)$, caregiving burden $(\beta=-0.289)$ and family functioning $(\beta=0.268)$ $\left(F=45.778, p=0.000, R^{2}=0.542\right)($ shown in Table 7).

\section{Care-Giving Experiences of Family Caregivers}

Iterative data analysis revealed four major themes: (a) lack of knowledge about depression, (b) being overwhelmed emotionally with psychological burden-guilt, worry about suicidal behavior and concern about future, (c) the devastating impact of illness on family - heavy family financial burden, disruption of family life, and impaired family health, and (d) the perceived benefits of caregiving-learning to reflect, having family relationships improved and recognizing what is important in life. Some examples of each theme are below.

\section{Theme I: Lack of Knowledge About Depression}

In this study, most caregivers of AWD did not know or had little knowledge of depression. A 63-year-old grandmother said,

She (sick granddaughter) didn't want to study and was very lazy. She played with her mobile phone at home everyday, we didn't know this kind of disease (depression) in the countryside. (No. 8)

\section{Theme 2: Being Overwhelmed with Psychological Burden}

A 43-year-old mom with deep guilt described,

I was responsible for her illness. As a mother, I did very bad. I didn't discipline her when she was in junior high school. She had a little sister at that time. I thought that she was an adult and she did not have the need to talk to 
me. Gradually, she began to indulge in computer games and comics. (No.4)

AWD had a high risk of suicidal tendencies, which was a major concern of the caregivers. A 44-year-old father said,

Am worry about his (depressed son) suicidal behavior. He tried to kill himself once before, taking rat poison. We did not find out in time. The rat poison had a bad effect on his liver and spleen. (No. 3)

Caregivers were concerned about the future life of their AWD, including future work, marriage, etc. A 48-year-old mother expressed her concern, "I worry about her (sick daughter) illness if not cured on the end. I worry about her life, study, and later future into the society." (No.1)

Theme 3: The Devastating Impact of Illness on Family Many caregivers reported difficulty coping with these stressors because of financial burden. One unemployed father stated,

I didn't earn much outside work. Taking care of him (depressed son) resulted in having no time to earn money. His hospitalization cost a lot of money and the family expenses were very high. (No. 3)

The reduction in normal family life was not just due to insufficient time and energy, but also due to the caregiver's depleted emotional stamina. A 42-year-old mother said, "In the past, I went out with my friends to go shopping and chatting, but now I don' t have the time anymore." (No. 12)

Caregivers were so much involved in the delivery of care to their child that they often forgot their own personal health. A 38 years old mother said,

I can' $t$ sleep at night now and wake up two or three times in the middle. I didn' $t$ feel like a meal. (no appetite). [crying]" (No.7)

\section{Theme 4: The Perceived Benefits of Care-Giving}

With the gradual acceptance of depression in family, family caregivers were learning to reflect. A mother with a physical QoL score of 77.75 and a mental QoL score of 90.00 reflected and said,

Now I become more patient with my daughter. I would like to praise her appropriately. I used to lose my temper. Now I care about her emotions. My temper is much better than before. (No. 1)
For caregivers who were parents, care-giving improved the marital relationship. A mother with a physical QoL score of 85.50 and a mental QoL score of 86.75 described, "I always had some disagreements with my husband. However, this time my baby is sick. It is also a good time for me to talk with my husband."(No. 12)

Taking care of AWD often made caregivers realize that the most important thing in life is health rather than money or social status. A mother with a physical QoL score of 74.00 and a mental QoL score of 83.13 said,

We realized that physical health is the most important. As long as people are healthy, other (superficial) aspects (of life) are not so important. What can be abandoned should be abandoned. (No.2)

\section{Discussion}

Consistent with prior studies about the QoL among caregivers of adults with depression in China, ${ }^{16,23}$ the QoL among caregivers of AWD was significantly lower than the QoL among the general population. ${ }^{24}$ Caregivers' qualitative descriptions about their QoL also matched their quantitative ratings of QoL. They described how their QoL was affected by giving care to AWD, including being overwhelmed emotionally with psychological burden and the devastating impact of illness on family. Interestingly, caregivers of AWD had higher QoL than caregivers of adults with depression in several domains including physical function, social function and mental health. However, in role-emotional, caregivers of AWD had lower QoL than caregivers of adults with depression. ${ }^{23}$ This finding could be linked to the characteristics of the present sample. Compared with adults with depression, AWD are in the rebellious period of youth and have unstable emotions, which will lead to the deterioration of parent-child relationship quality and the intensification of parent-child conflict. ${ }^{38,39}$ Hence, family caregivers of AWD may have a lower emotional functioning.

Low family functioning of caregivers was associated with lower QoL among caregivers of AWD, which was a novel finding of this study. Depression had a devastating impact on caregivers' family functioning, the concrete manifestations in our qualitative results were heavy family financial burden, disruption of family life, and impaired family health. AWD was a chronic source of conflict within the family, which led to decreased communication between AWD and family caregivers, resulting in poor 
family functioning of caregivers. ${ }^{19}$ A recent study has found that primary caregivers' QoL was significantly lower than the rest of the family members' QoL among families with a sick child. ${ }^{40}$ Mental health-care personnel should provide professional assessments for the entire family, and call on other family members to support the primary caregivers more in order to improve the primary caregivers' family functioning and QoL. ${ }^{41}$

Similar to other studies, ${ }^{42}$ the positive emotion of caregivers was associated with better QoL among caregivers of AWD. This finding may be explained by the qualitative result in this study. Although some caregivers of AWD in this study found care-giving to be overwhelming, other caregivers with higher QoL reported that care-giving had some benefits such as learning to reflect, having family relationships improved and recognizing what is important in life. This positive side of care-giving has been described by other populations and was named "Caregiver Benefit Finding". ${ }^{20}$ Mental healthcare personnel should pay special attention to the "Caregiver Benefit Finding" that enhance positive emotion of caregivers, thereby improving the perception of care-giving burden and family functioning. ${ }^{43}$

Caregivers' mental QoL was most influenced by the suicide history of the AWD. These caregivers were always worried about their child's suicide attempts, which resulted in heavy psychological burden. Previous studies indicated that the high risk of suicide among AWD increased caregivers' supervision of AWD and in turn decreased caregivers' emotional well-being and increased their stress. ${ }^{44,45}$ Moreover, the negative emotion was also associated with poorer mental QoL among caregivers of AWD, which were supportive of the findings of the qualitative data in this study. The caregivers often felt guilt about their child's illness and were concerned about their future, which resulted in their feeling overwhelmed by care-giving.

Our findings also showed that caregivers with a higher education level reported better QoL than caregivers with a lower education level reported. Higher education level may help caregivers have a better knowledge of the disease of depression and have more coping ability to deal with care-giving. ${ }^{46}$ Lower knowledge of the disease of depression and higher depression stigma impacted more negative parental emotions. ${ }^{47}$ Furthermore, caregivers with a higher education level obtained better well-paying jobs that helped to support the cost of depression treatments. ${ }^{48}$

Admittedly, there are several limitations of this study. Since all adolescents with depression we investigated were in convalescence diagnosed by the doctor, so we did not consider their depressive symptoms as a factor of caregivers' QoL and did not collect the depressive symptoms of AWD. Data were collected at one point in time, and thus causality between the QoL among caregivers of AWD and influential factors cannot be assumed. A general rather than a caregiverspecific QoL tool was used and the results may not be a true reflection of caregivers' QoL. The ability to use a specific caregivers' QoL tool, such as the Chinese version of Caregivers' Qol was limited by a lack of sufficient psychometric properties. The qualitative interviews with caregivers of AWD, however, support the quantitative QoL findings. Similar to other studies, ${ }^{18}$ the non-probability sample may not be representative of China since it was conducted only in Changsha, Hunan, which limits the study's external validity and generalization of the findings. Further studies should be conducted in other regions and multiple sites in China. Lastly, this was a cross-sectional, observational study. A recommendation for future study is a randomized and controlled study to further assess QoL among caregivers of AWD.

\section{Conclusion}

The QoL among family caregivers of AWD in China was low, which was embodied in lack of knowledge about depression, being overwhelmed emotionally with psychological burden, the devastating impact of illness on family. Caregivers' QoL was influenced by the course of disease and suicide history of AWD, caregivers' educational qualification, family functioning, caregivers' burden, positive affect, and negative affect. In addition, caregivers with higher scores in QoL were found with the perceived benefits of care-giving. Based on these results, we recognize that there is an urgent need to build some well-trained teams of mental health-care professionals to provide psychological assistance and professional information to caregivers of AWD. Furthermore, health-care personnel should also guide these caregivers to perceive the benefits of care-giving to improve their family functioning.

\section{Ethics Approval and Informed Consent}

All procedures performed in studies involving human participants were in accordance with the ethical standards of the institutional research committee (IRB of behavioral and nursing research in School of Nursing of Central South University, IRB Approval Number: 2,017,044) and with the 1964 Helsinki declaration and its later 
amendments or comparable ethical standards. All participants in the study received written informed consent, including the publication of their responses.

\section{Acknowledgment}

Thanks to Prof Paula Milone-Nuzzo for proofreading (Prof Paula is the president of MGH Institute of Health Professions, PhD, RN, FHHC, FAAN).

\section{Funding}

This research was funded by the Social Science Foundation of Hunan Province (Grant No. 18YBA439).

\section{Disclosure}

The authors declare that they have no conflicts of interest in this work.

\section{References}

1. Siu AL. Screening for depression in children and adolescents: US preventive services task force recommendation statement. Pediatrics. 2016;137(3):e20154467. doi:10.1542/peds.2015-4467

2. Polanczyk GV, Salum GA, Sugaya LS, Caye A, Rohde LA. Annual research review: a meta-analysis of the worldwide prevalence of mental disorders in children and adolescents. $J$ Child Psychol Psychiatry. 2015;56(3):345-365. doi:10.1111/jcpp.12381

3. Xu DD, Rao WW, Cao XL, et al. Prevalence of major depressive disorder in children and adolescents in China: a systematic review and meta-analysis. J Affect Disord. 2018;241:592-598. doi:10.1016/j. jad.2018.07.083

4. Bahls SC. Depression in childhood and adolescence: clinical features. J Pediatr (Rio J). 2002;78(5):359-366.

5. Fernando K, Carter JD, Frampton CM, et al. Childhood-, teenage-, and adult-onset depression: diagnostic and individual characteristics in a clinical sample. Compr Psychiatry. 2011;52(6):623-629. doi:10.1016/j.comppsych.2010.12.006

6. MacQueen GM, Frey BN, Ismail Z, et al. Canadian Network for Mood and Anxiety Treatments (CANMAT) 2016 clinical guidelines for the management of adults with major depressive disorder: section 6. Special populations: youth, women, and the elderly. Can J Psychiatry. 2016;61(9):588-603. doi:10.1177/0706743716659276

7. Li C, Miao J, Gao X, et al. Factors associated with caregiver burden in primary caregivers of patients with adolescent scoliosis: a descriptive cross-sectional study. Med Sci Monit. 2018;24:6472-6479. doi:10.12659/MSM.909599

8. Yang X, Byrne V, Chiu MY. Caregiving experience for children with intellectual disabilities among parents in a developing area in China. J Appl Res Intellect Disabil. 2016;29(1):46-57. doi:10.1111/jar.12157

9. Perez AG, MacPherson HA, Youngstrom EA, et al. Parenting stress among caregivers of children with bipolar spectrum disorders. $J$ Clin Child Adolesc Psychol. 2018;47(1):306-320. doi:10.1080/ 15374416.2017.1280805

10. Radfar M, Ahmadi F, Fallahi KM. Turbulent life: the experiences of the family members of patients suffering from depression. J Psychiatr Ment Health Nurs. 2014;21(3):249-256. doi:10.1111/ jpm.12077

11. Darmi E, Bellali T, Papazoglou I, Karamitri I, Papadatou D. Caring for an intimate stranger: parenting a child with psychosis. J Psychiatr Ment Health Nurs. 2017;24(4):194-202. doi:10.1111/jpm.12367
12. Ndikuno C, Namutebi M, Kuteesa J, Mukunya D, Olwit C. Quality of life of caregivers of patients diagnosed with severe mental illness at the national referral hospitals in Uganda. BMC Psychiatry. 2016;16 (1):400. doi:10.1186/s12888-016-1084-2

13. Caqueo-Urizar A, Alessandrini M, Urzua A, Zendjidjian X, Boyer L, Williams DR. Caregiver's quality of life and its positive impact on symptomatology and quality of life of patients with schizophrenia. Health Qual Life Outcomes. 2017;15(1):76. doi:10.1186/s12955-0170652-6

14. Jalenques I, Cleret M, Richard B, Rondepierre F, Auclair C. Spouses' health-related quality of life evaluation of elderly patients with depression. Presse Medicale. 2017;46(11):249-258. doi:10.1016/j. lpm.2016.07.027

15. Boyer L, Baumstarck K, Alessandrini M, et al. Emotional intelligence and coping strategies as determinants of quality of life in depressed patient-caregiver dyads: an actor-partner interdependence analysis. Compr Psychiatry. 2017;74:70-79. doi:10.1016/j. comppsych.2017.01.003

16. Wu ZJ, Liu QY. Psychological state and quality of life of the major depressed patients' relatives. Chin J Health Psychol. 2018;26 (03):330-333. doi:10.13342/j.cnki.cjhp.2018.03.004

17. Zhang Y, Tang GF. Study on quality of life of family members of depression patients. Mod Preventive Med. 2005;32(12):1700-1701. doi:10.3969/j.issn.1003-8507.2005.12.059

18. Leng A, Xu C, Nicholas S, Nicholas J, Wang J. Quality of life in caregivers of a family member with serious mental illness: evidence from China. Arch Psychiatr Nurs. 2019;33(1):23-29. doi:10.1016/j. apnu.2018.08.010

19. Li ZJ. Family functioning of patients with depression and their family members. J Tongji Med Univ. 2013;34(01):103-107. doi:10.3969/j. issn1008-0392.2013.01.024

20. Lum HD, Lo D, Hooker S, Bekelman DB. Caregiving in heart failure: relationship quality is associated with caregiver benefit finding and caregiver burden. Heart Lung. 2014;43(4):306-310. doi:10.1016/ j.hrtlng.2014.05.002

21. Barbour RS. The case for combining qualitative and quantitative approaches in health services research. J Health Serv Res Policy. 1999;4(1):39-43. doi:10.1177/135581969900400110

22. Ni P, Chen JL, Liu N. The sample size estimation hi quantitative nursing research. Chin J Nurs. 2010;45(4):378-380. doi:10.3761/j. issn.0254-1769.2010.04.037

23. Huang ZH, Yang LQ. Family functioning in patients with depression and quality of life of caregivers. Mod Med J China. 2011;13 (10):42-44. doi:10.3969/j.issn.1672-9463.2011.10.015

24. Pan TF, Si CZ, He HJ, Wang B, Shan GL. Survey of health-related quality of life in population of 6 Chinese cities. Basic Clin Medicine. 2011;06:636-641. doi:10.16352/j.issn.10016325.2011.06.004

25. Moser A, Korstjens I. Series: practical guidance to qualitative research. Part 3: sampling, data collection and analysis. Eur J Gen Pract. 2018;24(1):9-18. doi:10.1080/13814788.2017.1375091

26. Ware JE, Sherbourne CD, The MOS. 36-item short-form health survey (SF-36). I. Conceptual framework and item selection. Med Care. 1992;30(6):473-483. doi:10.1097/00005650-199206000-00002

27. Li TC, Lee YD, Lin CC, Amidon RL. Quality of life of primary caregivers of elderly with cerebrovascular disease or diabetes hospitalized for acute care: assessment of well-being and functioning using the SF-36 health questionnaire. Qual Life Res. 2004;13 (6):1081-1088. doi:10.1023/B:QURE.0000031349.25124.d6

28. Li L, Wang H, Shen Y. Chinese SF-36 health survey: translation, cultural adaptation, validation, and normalisation. J Epidemiol Community Health. 2003;57(4):259-263. doi:10.1136/jech.57.4.259

29. Watson D, Clark LA, Tellegen A. Development and validation of brief measures of positive and negative affect: the PANAS scales. $J$ Pers Soc Psychol. 1988;54(6):1063-1070. doi:10.1037/00223514.54.6.1063 
30. Fianco A, Sartori RD, Negri L, Lorini S, Valle G, Delle FA. The relationship between burden and well-being among caregivers of Italian people diagnosed with severe neuromotor and cognitive disorders. Res Dev Disabil. 2015;39:43-54. doi:10.1016/j. ridd.2015.01.006

31. Huang L, Yang TZ, Ji ZM. Applicability of the positive and negative affect scale in Chinese. Chin Ment Health J. 2003;01:54-56.

32. Zarit SH, Reever KE, Bach-Peterson J. Relatives of the impaired elderly: correlates of feelings of burden. Gerontological. 1980;20 (6):649-655. doi:10.1093/geront/20.6.649

33. Yu Y, Liu ZW, Zhou W, et al. Cutoff of the zarit burden interview in predicting depression and anxiety. Qual Life Res. 2019;28 (9):2525-2533. doi:10.1007/s11136-019-02208-7

34. Lu L, Wang L, Yang X, Feng Q. Zarit caregiver burden interview: development, reliability and validity of the Chinese version. Psychiatry Clin Neurosci. 2009;63(6):730-734. doi:10.1111/j.14401819.2009.02019.x

35. Smilkstein G. The family APGAR: a proposal for a family function test and its use by physicians. J Fam Pract. 1978;6(6):1231-1239.

36. Zhang Z, Deng H, Chen Y, et al. Cross-sectional survey of the relationship of symptomatology, disability and family burden among patients with schizophrenia in Sichuan, China. Shanghai Arch Psychiatry. 2014;26(1):22-29. doi:10.3969/j.issn.10020829.2014.01.004

37. Yang TT, Tong YQ, Yin XX, Lu ZX, Gong YH. Evaluation of morisky medication adherence scale and family APGAR applied to patients with tuberculosis. Chin J Social Med. 2016;033 (006):580-582. doi:10.3969/j.issn.1673-5625.2016.06.024

38. Chen Q, Du W, Gao Y, et al. Analysis of family functioning and parent-child relationship between adolescents with depression and their parents. Shanghai Arch Psychiatry. 2017;29(6):365-372. doi:10.11919/j.issn.1002-0829.217067

39. Tompson MC, Connor EEO, Kemp GN, Langer DA, Asarnow JR. Depression in childhood and early adolescence: parental expressed emotion and family functioning. Ann Depress Anxiety. 2015;2(7).

40. Everhart RS, Greenlee JL, Winter MA, Fiese BH. Primary and secondary caregiver reports of quality of life in pediatric asthma: are they comparable? Appl Res Qual Life. 2018;13(2):371-383. doi:10.1007/s11482-017-9528-5
41. Ribé M, Salamero M, Pérez-Testor C, et al. Quality of life in family caregivers of schizophrenia patients in spain: caregiver characteristics, caregiving burden, family functioning, and social and professional support. Int $J$ Psychiatry Clin Pract. 2018;22(1):25-33. doi:10.1080/13651501.2017.1360500

42. Gardner MH, Mrug S, Schwebel DC, Phipps S, Whelan K, MadanSwain A. Benefit finding and quality of life in caregivers of childhood cancer survivors: the moderating roles of demographic and psychosocial factors. Cancer Nurs. 2017;40(5):28-37. doi:10.1097/ NCC.0000000000000419

43. Mei Y, Wilson S, Lin B, Li Y, Zhang Z. Benefit finding for Chinese family caregivers of community-dwelling stroke survivors: a cross-sectional study. J Clin Nurs. 2018;27(7-8):e1419-e1428. doi:10.1111/jocn.14249

44. Straub J, Keller F, Sproeber N, Koelch MG, Plener PL. Suicidal behavior in german adolescents. Prevalence and association with depressive and manic symptoms. Z Kinder Jugendpsychiatr Psychother. 2015;43(1):39-45. doi:10.1024/1422-4917/a000331

45. Bodner N, Kuppens P, Allen NB, Sheeber LB, Ceulemans E. Affective family interactions and their associations with adolescent depression: a dynamic network approach. Dev Psychopathol. 2018;30 (4):1459-1473. doi:10.1017/S0954579417001699

46. Inogbo CF, Olotu SO, James BO, Nna EO. Burden of care amongst caregivers who are first degree relatives of patients with schizophrenia. Pan Afr Med J. 2017;28:284. doi:10.11604/ pamj.2017.28.284.11574

47. Johnco C, Rapee RM. Depression literacy and stigma influence how parents perceive and respond to adolescent depressive symptoms. $J$ Affect Disord. 2018;241:599-607. doi:10.1016/j.jad.2018.08.062

48. Zeng Y, Zhou Y, Lin J. Perceived burden and quality of life in Chinese caregivers of people with serious mental illness: a comparison cross-sectional survey. Perspect Psychiatr Care. 2017;53(3):183-189. doi:10.1111/ppc.12151

49. Chinese Voice Online. Hunan: it took a per capita income of 3026 yuan to lift people out of poverty in 2016; 2016. December 2016. Available from: https://hunan.voc.com.cn/article/201612/ 201612111144378400.html. Accessed December 19, 2016.
Patient Preference and Adherence

\section{Publish your work in this journal}

Patient Preference and Adherence is an international, peer-reviewed, open access journal that focusing on the growing importance of patient preference and adherence throughout the therapeutic continuum. Patient satisfaction, acceptability, quality of life, compliance, persistence and their role in developing new therapeutic modalities and compounds to optimize clinical outcomes for existing disease states are major areas of interest for the journal. This journal has been accepted for indexing on PubMed Central. The manuscript management system is completely online and includes a very quick and fair peer-review system, which is all easy to use. Visit http:// www.dovepress.com/testimonials.php to read real quotes from published authors. 